\title{
Development of functional dendrisomes based on a single molecule of polyesterbenzylether dendrimer and their application in cancer stem cell therapy
}

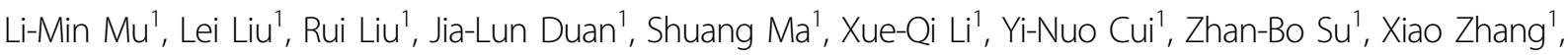 \\ Jian-Xing $\mathrm{Hu}^{1}$, Ying Xie', Ying Zheng ${ }^{2}$ and Wan-Liang Lu'
}

\begin{abstract}
The differentiation therapy of breast cancer stem cells (CSCs) represents a significant strategy to treat cancer, but inefficient delivery to CSCs hinders the efficacy of differentiation agents. In this work, we report a type of functional dendrisomes constructed by the synthesized amphiphilic dendrimers, which enhance cellular uptake by breast CSCs, differentiate breast CSCs by carrying all-trans retinoic acid (ATRA), and increase the anticancer efficacy by carrying ATRA and docetaxel (DTX) in vitro and in breast cancer-bearing mice. The study further reveals the mechanism of cellular uptake by breast CSCs and uncovers the differentiation mechanism by analyzing relevant signal molecules, transcription factors, and cell cycle-associated signaling pathways during differentiation therapy in breast CSCs. Hence, this study offers a novel type of functional dendrisomes for differentiation therapy of breast CSCs and has significant clinical implications.
\end{abstract}

\section{Introduction}

Cancer stem cells (CSCs) are initiator cancer cells that possess the capability to generate all types of cells. Such cells may give rise to mature cancer cells through selfrenewal and differentiation ${ }^{1}$. CSCs have been identified in breast cancer ${ }^{2,3}$ as a subset of cells that cause relapse and metastasis by producing new tumors ${ }^{4}$. CSCs exist in the vicinity or the inside of tumor tissue, often stay at rest, express high levels of ATP-binding cassette transporters (ABC transporters $)^{5}$ and have strong DNA repair ability ${ }^{6}$, leading to the insensitivity to chemotherapy and radiotherapy ${ }^{7}$.

We hypothesize that a differentiation therapy with functional dendrisomes enhances the cellular uptake of

\footnotetext{
Correspondence: Wan-Liang Lu (luwl@bjmu.edu.cn)

${ }^{1}$ State Key Laboratory of Natural and Biomimetic Drugs, Beijing Key Laboratory of Molecular Pharmaceutics and New Drug System, School of Pharmaceutical Sciences, Peking University, Beijing, China

${ }^{2}$ Institute of Chinese Medical Sciences, University of Macau, Macau, China
}

CSCs, differentiates CSCs by carrying all-trans retinoic acid (ATRA), and improves the prognosis of chemotherapy by carrying ATRA and docetaxel (DTX).

Dendrimer is a repetitively branched molecule that has been used as a drug carrier for anticancer treatment ${ }^{8,9}$. However, its drug loading capacity is restricted by its limited inner space and unsealed surface. To address this issue, we synthesized an amphiphilic dendrimer, which was further constructed into a vesicle by inserting a lipid derivative and cholesterol, named as dendrisome.

Distearoylphosphatidyl ethanolamine polyethylene glycol (DSPE-PEG ${ }_{2000}$ ) is a pegylated lipid derivative that is used to extend the circulation of drug carriers in the body to evade the rapid clearance of the reticuloendothelial (RES) system $^{10}$ and to enhance the permeability and retention (EPR) effect ${ }^{11}$ in solid tumors. To enhance cellular uptake by breast CSCs, DSPE-PEG ${ }_{2000}$ was conjugated with a D-type hexa-arginine $\left({ }^{\mathrm{d}} \mathrm{R}_{6}\right)$ peptide ${ }^{12}$. The resultant product (DSPE-PEG $2000^{-}{ }^{\mathrm{d}} \mathrm{R}_{6}$ ) was inserted into 
the dendrimer to form functional dendrisomes. In addition, cholesterol was inserted into functional dendrisomes to modulate membrane fluidity over the range of physiological temperatures ${ }^{13}$.

ATRA is a ligand of the retinoic acid receptor (RAR) ${ }^{14}$, which can heterodimerize with retinoid $\mathrm{X}$ receptors (RXRs) and further bind with retinoic acid response elements (RAREs) in the genome to regulate the gene expression of cells. Studies have demonstrated that ATRA is able to promote the maturation of blast cells in the treatment of acute promyelocytic leukemia ${ }^{15}$, exhibiting the potential to induce the differentiation of $\mathrm{CSCs}^{16}$. DTX is a chemotherapeutic agent that is clinically used in the treatment of a variety of tumors by inhibiting microtubule depolymerization ${ }^{17}$. However, DTX has been extensively experienced with drug resistance in the clinical treatment of breast cancer ${ }^{18}$.

The objectives of this study were to develop a functional dendrisome for differentiation therapy of breast CSCs and to reveal the mechanism involved. Transcriptome microarrays with unsupervised hierarchical clustering and gene ontology (GO) analyses were used to profile the differentiation. In addition, real-time qRT-PCR, flow cytometry, and western blotting were used to reveal relevant signal molecules, transcription factors, surface markers, biological processes, and signaling pathways.

\section{Materials and methods Materials}

Docetaxel was purchased from Nanjing Xiezun Chemicals (Nanjing, China), $\mathrm{PEG}_{2000}$-DSPE and NHS$\mathrm{PEG}_{2000}$-DSPE were purchased from NOF Corporation (Kanagawa, Japan), and the ${ }^{\mathrm{d}} \mathrm{R}_{6}$ peptide was synthesized by Hefei Bankpeptide Company Ltd. (Hefei, China).

MCF-7 and MDA-MB-435S breast cancer cells were purchased from the Institute of Basic Medical Sciences, Chinese Academy of Medical Sciences (Beijing, China), and cultured in Roswell Park Memorial Institute (RPMI) 1640 medium supplemented with $10 \%$ fetal bovine serum (FBS), $100 \mathrm{U} / \mathrm{mL}$ penicillin, and $100 \mu \mathrm{g} / \mathrm{mL}$ streptomycin. SK-BR-3 breast cancer cells were purchased from ZQXZ Biotech (Shanghai, China) and cultured in the Dulbecco's modified Eagle medium (DMEM) supplemented with 10\% FBS, $100 \mathrm{U} / \mathrm{mL}$ penicillin, and $100 \mu \mathrm{g} / \mathrm{mL}$ streptomycin. MCF-10A mammary gland epithelial cells were purchased from ZQXZ Biotech and cultured in the mammary epithelial cell medium (MEpiCM; ZQXZ Bio., Beijing, China) supplemented with $1 \%$ mammary epithelial cell growth supplement (MEpiCGS), $100 \mathrm{U} / \mathrm{mL}$ penicillin, and $100 \mu \mathrm{g} /$ $\mathrm{mL}$ streptomycin.

\section{Synthesis of amphiphilic dendrimers}

Methyl-3,4-dihydroxy-benzoate $(0.1 \mathrm{~mol})$ and $\mathrm{K}_{2} \mathrm{CO}_{3}$ $(0.4 \mathrm{~mol})$ were dissolved in dimethyl formamide (DMF, $100 \mathrm{~mL}$ ). The mixture was stirred at room temperature for $30 \mathrm{~min}$, and then bromododecane $(0.22 \mathrm{~mol})$ was added dropwise. The mixture was heated at $65^{\circ} \mathrm{C}$ for $3 \mathrm{~h}$ and evaporated by a rotary vacuum evaporator. The resultant product was washed with $\mathrm{H}_{2} \mathrm{O}$ and then dried to obtain a white solid product, methyl-3,4-(didodecyloxy)benzoate (MDB; $109.22 \mathrm{~g}, 98.41 \%$ yield, $\mathrm{Rf}=0.75$ ).

The above product (MDB, $0.1 \mathrm{~mol}$ ) was dissolved in a mixture of menthol and tetrahydrofuran (THF) $(150 \mathrm{~mL} /$ $150 \mathrm{~mL})$, and then $\mathrm{KOH}(0.25 \mathrm{~mol})$ was added. The mixture was heated at $70^{\circ} \mathrm{C}$ for $1 \mathrm{~h}$ and evaporated by a rotary vacuum evaporator. The resultant product was washed with $\mathrm{H}_{2} \mathrm{O}$ and petroleum ether (PE) and then dried to obtain a white solid product, 3,4-(didodecyloxy)-benzoic acid (DBA; $49.07 \mathrm{~g}, 99.98 \%$ yield, $\mathrm{Rf}=0.05$ ).

The above product (DBA, $0.05 \mathrm{~mol}$ ) was dissolved in dichloromethane $(400 \mathrm{~mL})$. Afterwards, ethylene glycol (0.2 mol), diphenyl-4-thiophenoxyphenyl sulfonium salt (DPTS, $0.025 \mathrm{~mol}$ ), and $\mathrm{N}, \mathrm{N}^{\prime}$-dicyclohexylcarbodiimide (DCC, $0.06 \mathrm{~mol}$ ) were added. The mixture was stirred at $25^{\circ} \mathrm{C}$ for $5 \mathrm{~h}$, washed with dichloromethane, and then purified by flash chromatography, producing a white solid product, 2-hydroxyethyl-3,4-(didodecyloxy)-benzoate (HEDB; $17.78 \mathrm{~g}, 66.49 \%$ yield, $\mathrm{Rf}=0.9$ ).

The above product (HEDB; $7.29 \mathrm{mmol}$ ) was dissolved in chloroform $(30 \mathrm{~mL})$. Then, dimethylolpropionic acid (DMPA; $8.73 \mathrm{mmol})$, DPTS $(3.65 \mathrm{~mol})$, and DCC $(8.74 \mathrm{mmol})$ were added to the solution. The mixture was heated at $70^{\circ} \mathrm{C}$ under reflux for $5 \mathrm{~h}$, and the mixture was filtered, washed with dichloromethane, and evaporated. The product was purified by flash chromatography, producing a white product, amphiphilic molecule-acetonide (AM-acetonide; $4.30 \mathrm{~g}, 85.34 \%$ yield, $\mathrm{Rf}=0.7$ ).

AM-acetonide $(31.48 \mathrm{mmol})$ was dissolved in THF $(120 \mathrm{~mL}) . \mathrm{HCl}(120 \mathrm{~mL} 6 \mathrm{M})$ was then added to the mixture. The mixture was stirred at $30^{\circ} \mathrm{C}$ for $1.5 \mathrm{~h}$ and then evaporated. The resultant product was further extracted with dichloromethane, and the organic phase was dried by anhydrous $\mathrm{Na}_{2} \mathrm{SO}_{4}$ and then evaporated, producing a white solid amphiphilic molecule (AM; $9.78 \mathrm{~g}, 87.32 \%$ yield, $\mathrm{Rf}=0.2$ ). AM was characterized by electrospray ionization mass spectrometry (ESI-MS) and nuclear magnetic resonance (NMR).

AM $(18.27 \mathrm{mmol})$ was dissolved in dichloromethane. DMPA $(40.18 \mathrm{mmol})$, DPTS $(18.27 \mathrm{~mol})$, and DCC (43.83 mmol) were subsequently added. The mixture was heated at $70^{\circ} \mathrm{C}$ under reflux for $5 \mathrm{~h}$, filtered, and washed with dichloromethane. The resultant product was evaporated, and the oil-like product was further purified by flash chromatography, producing a transparent colorless liquid, $\mathrm{AD}$-acetonide $(6.63 \mathrm{~g}, 37.67 \%$ yield, $\mathrm{Rf}=0.6)$.

AD-acetonide $(6.88 \mathrm{mmol})$ was dissolved in THF $(50 \mathrm{~mL})$, and then $\mathrm{HCl}(6 \mathrm{M}, 50 \mathrm{~mL})$ was added. The mixture was stirred at $30^{\circ} \mathrm{C}$ for $3 \mathrm{~h}$, evaporated, and extracted with dichloromethane. The organic phase was 
dried by anhydrous $\mathrm{Na}_{2} \mathrm{SO}_{4}$ and evaporated under a rotatory vacuum evaporator. The resultant product was amphiphilic dendrimer (AD), a thick colorless oil at room temperature and a white solid at lower temperature ( $3.91 \mathrm{~g}, 64.16 \%$ yield, $\mathrm{Rf}=0.3)$. AD was characterized by electrospray ionization mass spectrometry (ESI-MS) and nuclear magnetic resonance (NMR).

\section{Construction of functional dendrisomes}

To construct a functional dendrisome, lipid and cholesterol were inserted into the membrane of dendrimer vesicles. In addition, a D-type penetrating peptide ${ }^{\mathrm{d}} \mathrm{R}_{6}$ (Bankpeptide, Hefei, China) was conjugated to a pegylated lipid to enhance the long-circulation effect in the blood system ${ }^{19}$ and penetrate into cancer stem cells ${ }^{20}$. To reach these goals, ${ }^{\mathrm{d}} \mathrm{R}_{6}$ $(10 \mu \mathrm{mol})$ and DSPE-PEG 2000 -NHS $(10 \mu \mathrm{mol}$; NOF Corporation, Kanagawa, Japan) were dissolved in a mixture of DMF $(2 \mathrm{~mL})$ and $\mathrm{N}$-methylmorpholine $(200 \mu \mathrm{L})$. The mixture was stirred using a magnetic stirrer at room temperature for $48 \mathrm{~h}$ under nitrogen gas protection. Then, the crude product was transferred into a regenerated cellulose dialysis tubing (MWCO, $3000 \mathrm{Da}$ ) and dialyzed against deionized water for $24 \mathrm{~h}$. The mixture was freeze-dried, and the final product (DSPE-PEG $200{ }^{-}{ }^{\mathrm{d}} \mathrm{R}_{6}$ ) was obtained and confirmed by MALDI-TOF-MS (Shimadzu, Japan).

To screen for a kind of stable dendrisomes, $\mathrm{AM}$ or $\mathrm{AD}$ were dissolved in dichloromethane. The solvent was then evaporated, and the lipid film was hydrated with HEPES buffer solution (HBS, $25 \mathrm{mM}$ HEPES, $150 \mathrm{mM} \mathrm{NaCl}$ ) by sonication in a water bath for $5 \mathrm{~min}$. Afterwards, to compare their capability to form vesicles, the suspensions were treated with an ultrasonic cell disruptor for $10 \mathrm{~min}(200 \mathrm{~W})$, transferred into a regenerated cellulose dialysis tubing (MWCO, 8000-14,000 Da), and dialyzed in HBS for 24 h.

To construct regular dendrisomes, dendrimers, cholesterol, and DSPE-PEG 2000 were dissolved in dichloromethane at serial molar ratios (100:0:0, 90:10:4, 80:20:4, 70:30:4, and 60:40:4) in a pear-shaped bottle for screening purposes, and the same procedures as above were performed. To construct functional dendrisomes, DSPE$\mathrm{PEG}_{2000}{ }^{-}{ }^{\mathrm{d}} \mathrm{R}_{6}$ was used to replace DSPE-PEG 2000 .

To entrap the drug, ATRA, DTX, or both were added (dendrisome materials:drug $=20: 1, \mathrm{w} / \mathrm{w}$ ) with the lipid to obtain functional dendrisomes carrying ATRA, functional dendrisomes carrying DTX, and functional dendrisomes carrying ATRA and DTX.

The dendrisomes were measured using dynamic light scattering (DLS) with a Nano Series Zenith 4003 Zetasizer (Malvern Instruments Ltd., Malvern, UK), a transmission electron microscope (TEM; JEM-1400, JEOL Ltd., Tokyo, Japan), and an atomic force microscope (AFM; SPI3800N series SPA-400, NSK Ltd., Tokyo, Japan).

The contents of ATRA and DTX were measured by a high-performance liquid chromatography (HPLC) system
(Shimadzu, Japan). The mobile phase for measuring ATRA consisted of acetonitrile and $10 \%$ acetic acid solution $(96: 4, \mathrm{v} / \mathrm{v})$, and the detection wavelength was set at $350 \mathrm{~nm}$. The mobile phase for measuring DTX consisted of acetonitrile and water $(70: 30, \mathrm{v} / \mathrm{v})$, and the detection wavelength was set at $232 \mathrm{~nm}$.

The in vitro release rates of ATRA or DTX in the dendrisomes were determined by dialysis against phosphate buffered saline (PBS, $137 \mathrm{mM} \mathrm{NaCl}, 2.7 \mathrm{mM} \mathrm{KCl}$, $8 \mathrm{mM} \mathrm{Na}_{2} \mathrm{HPO}_{4}$ and $2 \mathrm{mM} \mathrm{KH_{2 }} \mathrm{PO}_{4}, \mathrm{pH}$ 7.4) containing $10 \%$ FBS. To evaluate stability, the functional dendrisomes were stored at $4{ }^{\circ} \mathrm{C}$, and the particle sizes were evaluated by DLS every other day.

\section{Cellular uptake}

To evaluate the cellular uptake of the dendrisomes, coumarin- 6 was used as a fluorescent probe for labeling them. Briefly, MCF-7 CSCs and SK-BR-3 CSCs were seeded in 12-well plates at a density of $2 \times 10^{5}$ cells/well and cultured for $24 \mathrm{~h}$. Then, the culture medium was replaced with fresh media containing coumarin-6 $(100 \mathrm{nM})$, dendrisomes carrying coumarin-6 (100 nM), or functional dendrisomes carrying coumarin-6 (100 nM). After incubation for $2 \mathrm{~h}$, the cells were collected, and the fluorescence intensity was measured by a flow cytometer (FCM; FACScan, Becton Dickinson, San Jose, CA, USA). The excitation and emission wavelengths were set at $488 \mathrm{~nm}$ and $530 \mathrm{~nm}$, respectively.

To further observe the cellular uptake in tumor spheres, MCF-7 CSCs and SK-BR-3 CSCs were seeded at a density of $1 \times 10^{3}$ cells/well in 96-well plates coated with $50 \mu \mathrm{L} 2 \%$ $(\mathrm{w} / \mathrm{v})$ agarose solution and cultured for 4 days. Afterwards, the culture media were replaced with fresh media containing free coumarin- $6(100 \mathrm{nM})$, dendrisomes carrying coumarin-6 $(100 \mathrm{nM})$, or functional dendrisomes carrying coumarin- $6(100 \mathrm{nM})$. After incubation for $2 \mathrm{~h}$, the spheres were transferred into glass-bottom dishes (Nest, Beijing, China; $\phi=15 \mathrm{~mm}$ ). The uptake by the spheres was evaluated using a confocal laser-scanning fluorescence microscope (Leica, Heidelberg, Germany).

\section{Endocytosis mechanism}

To reveal the endocytosis mechanism of dendrisomes, MCF-7 CSCs were seeded in 12-well plates at a density of $2 \times 10^{5}$ cells/well and cultured for $24 \mathrm{~h}$. The plates were treated as follows: one group was placed into a $4{ }^{\circ} \mathrm{C}$ refrigerator, and the other four groups were separately treated with fresh media containing methyl$\beta$-cyclodextrin $(6 \mathrm{mg} / \mathrm{mL})$, quercetin $(6 \mu \mathrm{g} / \mathrm{mL})$, chlorpromazine $(20 \mu \mathrm{g} / \mathrm{mL})$, or colchicine $(8 \mu \mathrm{g} / \mathrm{mL})$ for $1 \mathrm{~h}$. Afterwards, functional dendrisomes carrying coumarin- 6 (100 nM coumarin-6) were added into each plate. After incubation for $2 \mathrm{~h}$, the cells were collected, and the fluorescence intensity was measured by FCM. The 
excitation and emission wavelengths were set at $488 \mathrm{~nm}$ and $530 \mathrm{~nm}$, respectively.

\section{Colocalization into lysosomes}

To evaluate the capture of functional dendrisomes by lysosomes after pinocytosis, MCF-7 CSCs and SK-BR-3 CSCs were seeded in glass-bottom dishes at a density of $2 \times 10^{5}$ cells in each dish and cultured for $24 \mathrm{~h}$. Afterwards, dendrisomes carrying coumarin-6 $(100 \mathrm{nM})$ or functional dendrisomes carrying coumarin-6 (100 nM) were separately added into the dishes. After incubation for $2 \mathrm{~h}$, the cells were stained with Lyso-Tracker Deep Red (Invitrogen, Beijing, China) at $37^{\circ} \mathrm{C}$ for $30 \mathrm{~min}$. The colocalization effect was observed using a confocal laserscanning fluorescence microscope.

\section{Phenotypes of differentiation}

To evaluate differentiation, the phenotype markers (CD44, CD24, ABCG2, CXCR4, and EpCAM) of breast cancer cells, CSCs, and DMCs were studied. Briefly, MCF7, SK-BR-3, MCF-7 CSCs, SK-BR-3 CSCs, MCF-7 DMCs, and SK-BR-3 DMCs were collected and fixed using a $4 \%$ paraformaldehyde solution. Then, the cells were incubated for $30 \mathrm{~min}$ at room temperature with anti-human CD44 fluorescein isothiocyanate (FITC)-conjugated antibody, anti-human CD24 phycoerythrin (PE)-conjugated antibody, anti-human ABCG2 FITC-conjugated antibody, anti-human CXCR4 PE-conjugated antibody, and antihuman EpCAM allophycocyanin (APC)-conjugated antibody. As isotype controls, the cells were incubated with FITC-, PE-, or APC-conjugated mouse IgG. The fluorescence intensities were measured by FCM. The excitation wavelengths were set at $488 \mathrm{~nm}$ for FITC and PE and $633 \mathrm{~nm}$ for APC, and the emission wavelengths were set at $530 \mathrm{~nm}$ for FITC, $564 \mathrm{~nm}$ for PE, and $660 \mathrm{~nm}$ for APC. All antibodies were purchased from BioLegend (Beijing, China), and $5 \mu \mathrm{L}$ was added per test.

\section{In vivo imaging in breast cancer-bearing mice}

$\mathrm{DiR}$ was used as the fluorescent probe to indicate the distribution of functional dendrisomes in breast cancerbearing mice. The mice were randomly divided into four groups (three mice per group) and injected via the tail vein with $\mathrm{DiR}$, DiR dendrisomes, dendrisomes carrying DiR, or functional dendrisomes carrying DiR. After intravenous injection, the mice were scanned at 1, 3, 6, 12, 24 , and $48 \mathrm{~h}$ using an IVIS Spectrum Pre-Clinical In Vivo Imaging system (Perkin Elmer, Waltham, MA, USA). Afterwards, the mice were killed, and the major organs, including the hearts, livers, spleens, lungs, and kidneys, were isolated and photographed to observe the fluorescence signals.

The other experimental methods are provided in Supplementary Information.

\section{Results and discussion}

\section{Synthesis of amphiphilic dendrimers and fabrication of functional dendrisomes}

To develop a functional dendrisome, AM and AD were synthesized based on methyl-3,4-dihydroxy-benzoate (Fig. 1a) and screened according to the vesicle-forming property. Both products were confirmed using ESI-MS spectroscopy (Supplementary Figs. S1, S4), 1 H NMR (Fig. 1b1; Supplementary Figs. S2, S5) and $13 \mathrm{C}$ NMR (Fig. 1b2; Supplementary Figs. S3, S6). The ESI-MS, ${ }^{1} \mathrm{H}$ NMR, and ${ }^{13} \mathrm{C}$ NMR data of AD are as follows: (i) ESI+ MS, m/z: $905.6\left([\mathrm{M}+\mathrm{Na}]^{+}\right), \quad 921.6\left([\mathrm{M}+\mathrm{K}]^{+}\right) ; \quad$ (ii) ${ }^{1} \mathrm{H} \quad \mathrm{NMR}$ $\left(400 \mathrm{MHz}, \mathrm{CDCl}_{3}\right) \delta 7.61\left(\mathrm{dd},{ }^{3} \mathrm{~J}_{\mathrm{HH}}=8.4 \mathrm{~Hz},{ }^{4} \mathrm{~J}_{\mathrm{HH}}=\right.$ $\left.2.0 \mathrm{~Hz}, 1 \mathrm{H}, \mathrm{CH}_{\mathrm{Ar}}{ }^{\circ}\right), 7.52\left(\mathrm{~d},{ }^{4} \mathrm{~J}_{\mathrm{HH}}=1.7 \mathrm{~Hz}, 1 \mathrm{H}, \mathrm{CH}_{\mathrm{Ar}}{ }^{\circ}\right)$, $6.87\left(\mathrm{~d},{ }^{3} \mathrm{~J}_{\mathrm{HH}}=8.4 \mathrm{~Hz}, 1 \mathrm{H}, \mathrm{CH}_{\mathrm{Ar}}^{\mathrm{m}}\right), 4.50(\mathrm{~m}, 4 \mathrm{H}$, $\left.\mathrm{OCH}_{2} \mathrm{CH}_{2} \mathrm{O}\right), 4.43\left(\mathrm{~d},{ }^{2} \mathrm{~J}_{\mathrm{HH}}=11.1 \mathrm{~Hz}, 2 \mathrm{H}, \mathrm{G} 1-\mathrm{CCH}_{2} \mathrm{O}\right)$, $4.26\left(\mathrm{~d},{ }^{2} \mathrm{~J}_{\mathrm{HH}}=11.1 \mathrm{~Hz}, 2 \mathrm{H}, \mathrm{G} 1-\mathrm{CCH}_{2} \mathrm{O}\right), 4.04(\mathrm{~m}, 4 \mathrm{H}$, $\left.\mathrm{OCH}_{2}{ }^{\text {chain }}\right), 3.80\left(\mathrm{~m}, 4 \mathrm{H}, \mathrm{CH}_{2} \mathrm{OH}\right), 3.68(\mathrm{~m}, 4 \mathrm{H}$, $\left.\mathrm{CH}_{2} \mathrm{OH}\right), 3.37$ (bs, $\left.4 \mathrm{H}, \mathrm{OH}\right), 1.8-1.2\left(\mathrm{~m}, 40 \mathrm{H},\left[\mathrm{CH}_{2}\right]_{10}\right)$, $1.30\left(\mathrm{~s}, 3 \mathrm{H}, \mathrm{G} 1-\mathrm{CCH}_{3}\right), 1.03\left(\mathrm{G} 2-\mathrm{CCH}_{3}\right), 0.88\left(\mathrm{t},{ }^{3} \mathrm{~J}_{\mathrm{HH}}=\right.$ $\left.6.6 \mathrm{~Hz}, 6 \mathrm{H}, \mathrm{CH}_{3}{ }^{\text {chain }}\right)$; (iii) ${ }^{13} \mathrm{C} \mathrm{NMR}(100 \mathrm{MHz}, \mathrm{CDCl} 3), \delta$ 175.0 (CCO), 172.8 (CCO), 166.2 (ArCO), $153.6\left(\mathrm{C}_{\mathrm{Ar}}{ }^{\mathrm{p}}\right)$, $148.6\left(\mathrm{C}_{\mathrm{Ar}}{ }^{\mathrm{m}}\right), 123.7\left(\mathrm{CH}_{\mathrm{Ar}}{ }^{\circ} \mathrm{CH}_{\mathrm{Ar}}\right), 121.6\left(\mathrm{C}_{\mathrm{Ar}}{ }^{\mathrm{i}}\right), 114.3$ $\left(\mathrm{CH}_{\mathrm{Ar}}{ }^{\mathrm{m}}\right), \quad 111.9\left(\mathrm{CH}_{\mathrm{Ar}}{ }^{\circ} \mathrm{C}_{\mathrm{Ar}}\right), \quad 69.4\left(\mathrm{OCH}_{2}{ }^{\text {chain }}\right), \quad 69.0$ $\left(\mathrm{OCH}_{2}{ }^{\text {chain }}\right), 67.3\left(\mathrm{CH}_{2} \mathrm{OH}\right), 64.8\left(\mathrm{G} 1-\mathrm{CCH}_{2} \mathrm{O}\right), 63.3,62.0$ $\left(\mathrm{OCH}_{2} \mathrm{CH}_{2} \mathrm{O}\right), 49.8\left(\mathrm{CCH}_{2} \mathrm{OH}\right), 46.4\left(\mathrm{G} 1-\mathrm{CCH}_{2} \mathrm{O}\right), 32-22$ $\left(\left[\mathrm{CH}_{2}\right]_{16}\right), 18.0\left(\mathrm{G} 1-\mathrm{CH}_{3}\right), 17.1\left(\mathrm{G} 2-\mathrm{CH}_{3}\right), 14.1\left(\mathrm{CH}_{3}{ }^{\text {chain }}\right)$. The results demonstrated that the two molecules, AM and AD, were successfully synthesized.

To obtain stable dendrisomes, the vesicles fabricated by AM and AD were separately characterized by TEM and DLS. The results showed that the AM vesicles existed in polymorphous states of both rod-like vesicles and irregularly aggregated vesicles $(72.65 \pm 9.24 \mathrm{~nm})$ and were polydisperse with a broad size distribution (PDI $=0.429 \pm$ 0.024) (Supplementary Fig S7A1, A2). In contrast, the AD vesicles were evenly round in shape $(67.13 \pm 0.18 \mathrm{~nm})$ and were monodisperse with a narrow size distribution (PDI = $0.173 \pm 0.003$ ) (Supplementary Fig. S7B1, B2). Based on the superior vesicle-forming capability, $\mathrm{AD}$ was used for further investigation. The evaluation of the vesicle-forming critical value showed that the critical micelle concentration (CMC) of $\mathrm{AD}$ was $4.02 \mu \mathrm{M}\left(37^{\circ} \mathrm{C}\right.$, pH 7.4) (Supplementary Fig. S8).

To fabricate functional dendrisomes, cholesterol and a newly synthesized DSPE-PEG ${ }_{2000}{ }^{\mathrm{d}} \mathrm{R} 6$ (confirmed by MALDI-TOF-MS in Fig. 1c) were inserted into the AD vesicle. This fabrication aims at enabling the functional dendrisome to modulate membrane fluidity ${ }^{21}$, reduce rapid clearance by the RES system ${ }^{22,23}$ and enhance accumulation in tumor tissues ${ }^{24}$. In addition, a regular dendrisome was similarly prepared as a control by inserting DSPE-PEG 2000 .

The dendrisome materials were optimized at a fixed ratio (AD:cholesterol:DSPE-PEG 2000 or DSPE- 


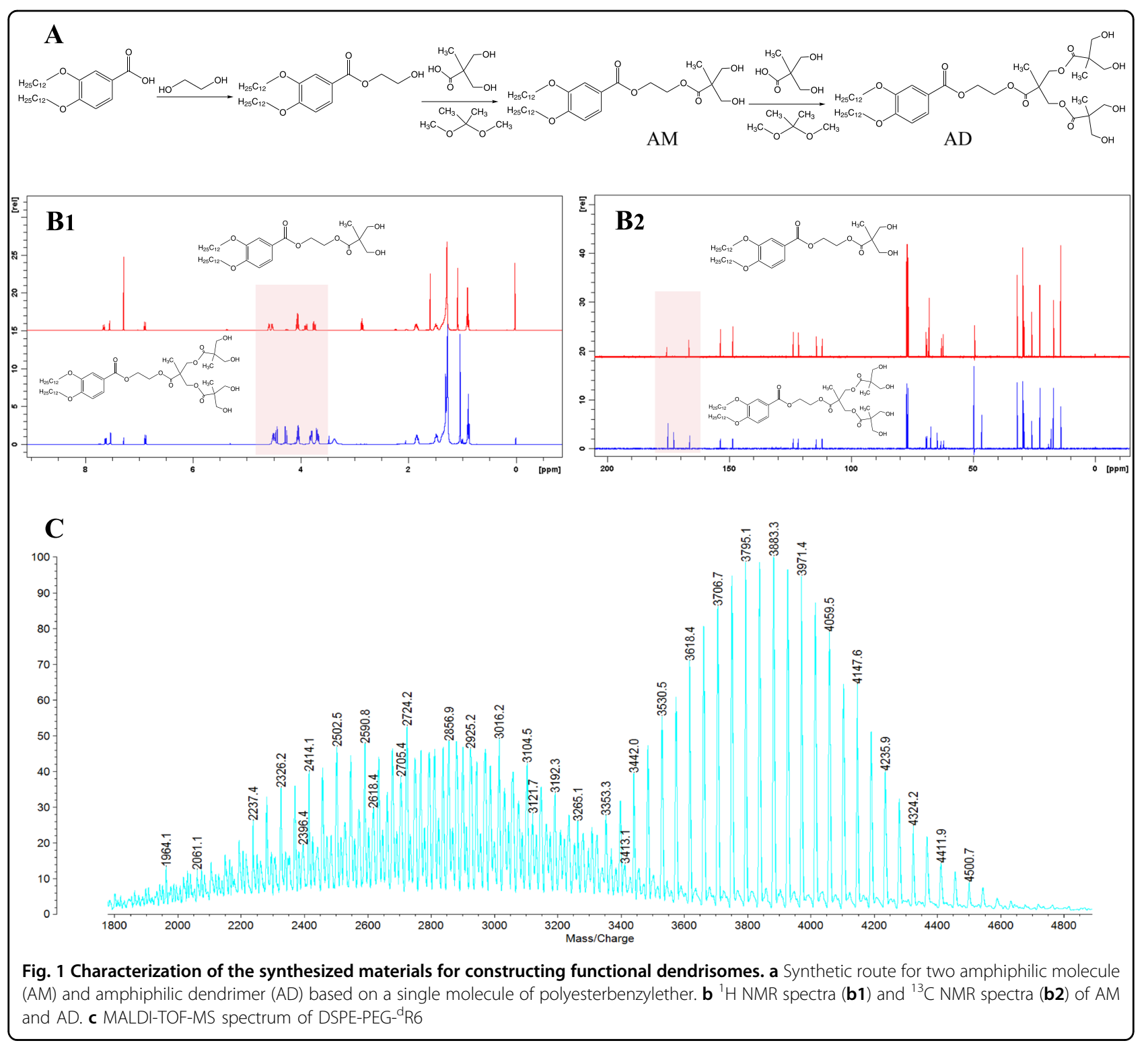

$\mathrm{PEG}_{2000^{-}}{ }^{\mathrm{d}} \mathrm{R} 6=80: 20: 4$, molar ratio) (Fig. 2b). Two types of dendrisomes were able to entrap ATRA, DTX, or both simultaneously (Fig. 2a).

The results from the TEM images, AFM images and size distributions indicated that both blank functional dendrisomes (Fig. 2c, a), and functional dendrisomes carrying ATRA and DTX (Fig. 2c, b) were round in shape with smooth surfaces and had uniform nanoscale sizes $(78.64 \pm 0.18 \mathrm{~nm} ; \quad 75.62 \pm 1.15 \mathrm{~nm})$ and positive zeta potential values $(0.18 \pm 0.09 \mathrm{mV} ; 0.19 \pm 0.08 \mathrm{mV})$. The encapsulation efficiencies of both ATRA and DTX by the dendrisomes were above $85 \%$ (Table 1).

The drug-release rates of ATRA and DTX in the initial $48 \mathrm{~h}$ were all below $40 \%$ in the phosphate buffered saline containing blood components (Supplementary Fig. S9A,
B). In addition, the particle sizes and PDI of functional dendrisomes were not significantly changed after 21 days of storage at $4{ }^{\circ} \mathrm{C}$ (Supplementary Fig. S10). The results demonstrated that the nanosized functional dendrisomes were successfully constructed and were able to carry ATRA and DTX stably.

\section{Functional dendrisomes enhance uptake by breast CSCs in vitro and accumulation in breast tumors in mice}

To understand cellular uptake, functional dendrisomes were separately labeled with two fluorescent probes (DiR and coumarin-6) in the vitro studies and in breast cancerbearing mice. The results from flow cytometry demonstrated that the functional dendrisomes significantly enhanced cellular uptake by breast CSCs (MCF-7 CSCs 


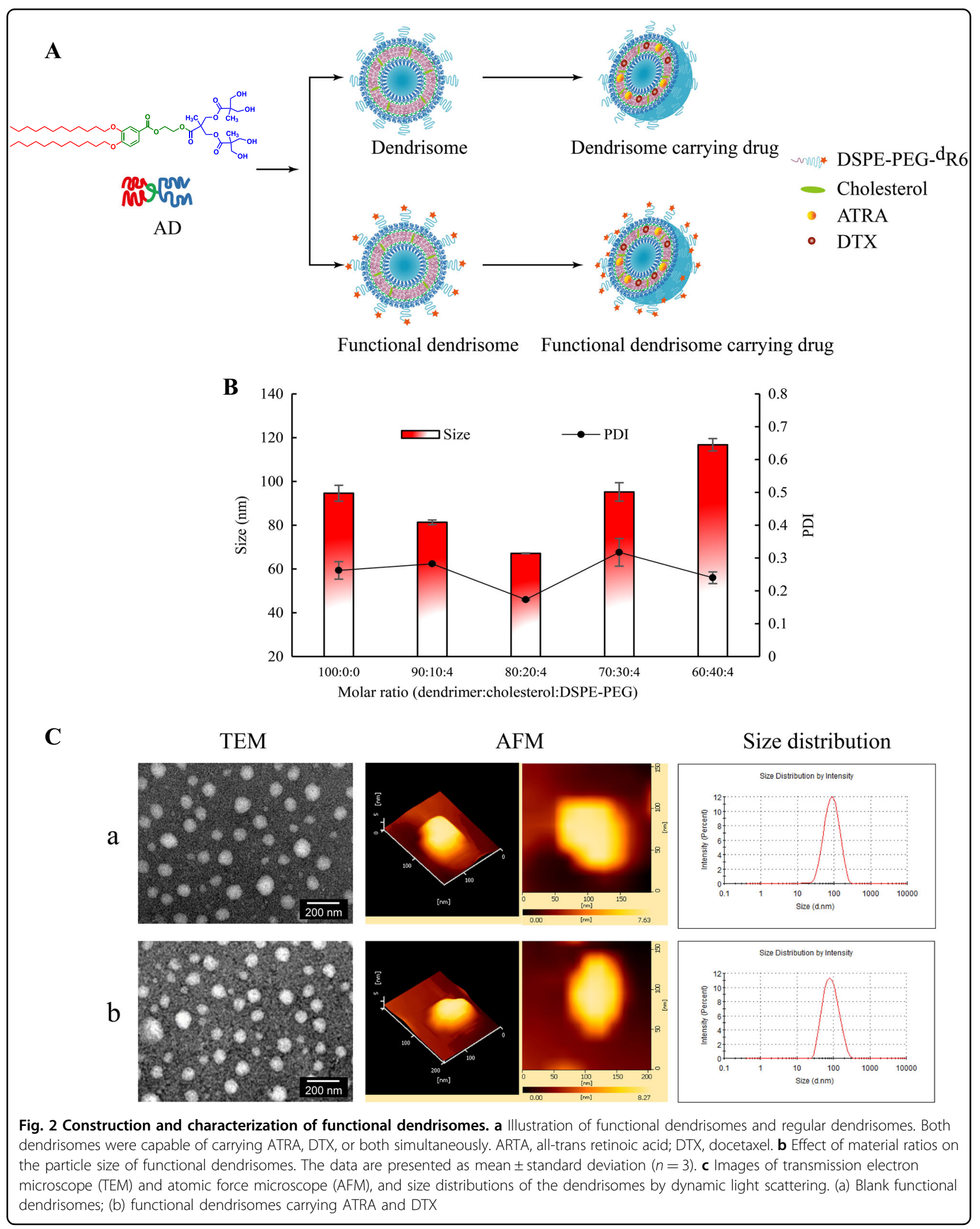


Table 1 Characterization of functional dendrisomes

\begin{tabular}{lllcc}
\hline Formulations & Particle size $(\mathbf{n m})$ & Polydispersity (PDI) & Zeta potential (mV) & Encapsulation efficiency (\%) \\
\hline Blank dendrisomes & $67.13 \pm 0.18$ & $0.173 \pm 0.003$ & $-0.24 \pm 0.05$ & $/$ \\
Blank functional dendrisomes & $78.64 \pm 0.18$ & $0.180 \pm 0.08$ & $0.18 \pm 0.09$ & $/$ \\
Functional dendrisomes carrying ATRA and DTX & $75.62 \pm 1.15$ & $0.175 \pm 0.014$ & $0.19 \pm 0.08$ & DTX: $86.62 \pm 0.15$ \\
& & & & ATRA: $88.51 \pm 0.65$ \\
\hline
\end{tabular}

The data are presented as mean \pm standard deviation $(n=3)$

and SK-BR-3 CSCs), exhibiting a 3.5- to 5-fold increase compared with that of the regular controls (Fig. 3a).

To further reveal the mechanism, endocytosis inhibitors were coapplied with functional dendrisomes to CSCs. The results showed that the temperature decrease (to $4{ }^{\circ} \mathrm{C}$ ) resulted in an evident decrease in cellular uptake; treatment with methyl- $\beta$-cyclodextrin $(\mathrm{M} \beta \mathrm{CD}$, caveolin inhibitor) or chlorpromazine (clathrin inhibitor) resulted in a significant decrease in uptake. In addition, treatment with quercetin (an independent inhibitor) also demonstrated a slight inhibitory effect on cellular uptake (Fig. 3b). However, treatment with colchicine (a macropinocytosis inhibitor) did not affect the cellular uptake by CSCs. These results indicated that the endocytosis of functional dendrisomes was mainly mediated by caveolin and clathrin. In this process, caveolin acts as a scaffolding protein to ferry the endocytosis of functional dendrisomes; as a formation of coated vesicles, clathrin acts to build small vesicles to transfer functional dendrisomes into the cells ${ }^{25-27}$. In addition, endocytosis is an energy-consuming process.

To understand the status after endocytosis, the colocalization of functional dendrisomes with lysosomes was studied. The results indicated that the functional dendrisomes accumulated less in lysosomes than in regular dendrisomes (Fig. 3c). The phenomenon could be explained by the following processes. After endocytosis of functional dendrisomes, the endosomes further fused with the lysosomes. In this process, the $\mathrm{pH}$ value decreased gradually to form an acidic compartment. If the functional dendrisomes possess a buffering capacity in the $\mathrm{pH}$ range, they can bind protons $\left(\mathrm{H}^{+}\right)^{28}$. Then, $\mathrm{v}$-ATPase was able to translocate even more protons to lysosomes accompanied by the entry of chloride ions and influx of water, resulting in an increase in osmotic pressure in the lysosomes and the swelling of lysosomes. This process is named as the proton-sponge effect and could lead to the escape of functional dendrisomes from lysosomes to the cytoplasm $^{29,30}$. The results from the titration assay showed that the functional dendrisomes exhibited a buffering capacity in the $\mathrm{pH}$ range of 5.11-6.81 and in the $\mathrm{pH}$ range of 10.24-12.14 (Supplementary Fig. S11). Based on the physiological conditions in the cells, the functional dendrisomes were able to give rise to the proton-sponge effect in the lysosomes, from which they finally escaped.
Consequently, the cellular uptake is illustrated by four major steps: endocytosis mediated by caveolin and clathrin; internalization by lysosomes followed by lysosomal escape; drug release from the dendrisomes; and drug uptake effect on a particular target (Fig. 3d). The released ATRA interacts specifically with cellular retinoic acidbinding protein (CRABP) and transports across the nuclei $^{31}$ to take effect. In the case of entrapping both ATRA and DTX simultaneously, the released DTX interacts with the microtubules in the cytoplasm of the CSCs.

The results demonstrated that both functional dendrisomes and regular dendrisomes had a strong capability to penetrate into the core of CSC spheres (MCF-7 CSCs and SK-BR-3 CSCs) (Fig. 3e). In contrast, free coumarin only penetrated into the periphery of the spheres. Most likely, the difference is due to the roles of the nanosize and electric charge of the dendrisomes.

To understand the real-time distribution in vivo, the functional dendrisomes were labeled with the fluorescent probe DiR and intravenously injected into breast cancerbearing mice. The results showed that the functional dendrisomes were able to accumulate in the tumor tissue and were retained up to $48 \mathrm{~h}$. In contrast, free DiR accumulated less in the tumor tissue, but was mainly distributed in the liver (Fig. 3f1). The results demonstrated that the functional dendrisomes had the strongest accumulation effect in tumor tissues (Fig. 3f2). In addition, all formulations were distributed in liver and spleen tissues, but less distributed in other organ tissues. This phenomenon can be explained by the contribution of both the suitable particle size and the modified cationic peptide ${ }^{d} R_{6}$ of the functional dendrisomes. Similar to solid tumor tissues, the CSC spheres in vitro also have a loose structure that allows the entrance of nanosized particles. Furthermore, the negatively charged CSC spheres are readily able to attract cationic particles.

Transcriptome profiling reveals the functional molecules and bioprocesses involved in the differentiation of breast CSCs

To profile the signal molecules, transcription factors, surface markers, and bioprocesses after treatment with functional dendrisomes carrying ATRA, a transcriptome 


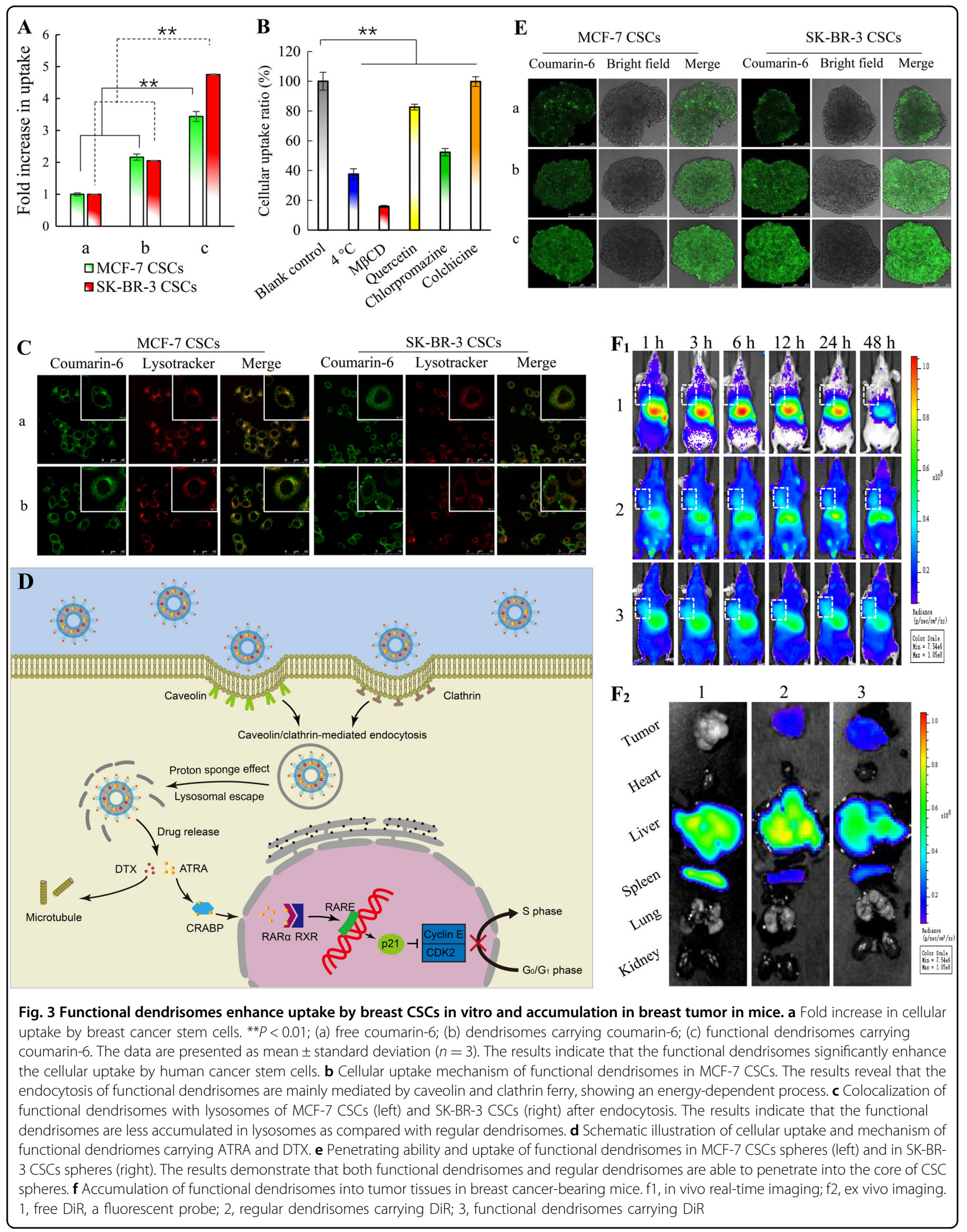


microarray with unsupervised hierarchical clustering and gene ontology $(\mathrm{GO})$ enrichment analyses were performed on the breast cancer cells, the CSCs, and the differentiated mature cells (DMCs).

The results showed that the functional dendrisomes carrying ATRA resulted in significant expression changes of 1578 genes (MCF-7 DMCs vs. MCF-7 CSCs, fold change $>2$ ). Furthermore, the results revealed that the CSCs were differentiated into DMCs, involving the upregulation of signal molecules (RAR $\alpha$, CALM3, CDKN1A, CDK7, NDC1, BMP2, etc.; Fig. 4a), transcription factors (POU5F1, OLIG3, TWIST 2, SNAIL1, etc.; Fig. 4b), and surface markers (FoxO3, etc.; Fig. 4c). However, differentiation also led to the downregulation of signal molecules (CDK2, CCNE, CTCFL, ID3, MAT1A, etc.), transcription factors (SOX15, SOX-6, POU2F1, KLF5, NANOG, etc.), and surface markers (CD44, CXCR4, NES, ALDH4A1, ALDH1L2, etc.). In addition, a variety of biological processes were involved in the differentiation of CSCs (Fig. 4d; Supplementary Table S1), in which the cell cycle was significantly involved.

\section{Phenotype analysis demonstrates the differentiation of breast CSCs in vitro and in cancer-bearing mice}

To further demonstrate the differentiation of breast CSCs after treatment with functional dendrisomes carrying ATRA, stem cell markers, including CD44 and CD24 (Fig. 5a1; Supplementary Fig S12A, B), CXCR4 (Fig. 5a2), ABCG2 (Fig. 5a3), and EpCAM (Fig. 5a4), were measured in the CSCs in vitro and in the breast cancerbearing mice.

$\mathrm{CD} 44^{+} \mathrm{CD} 24^{-}$has been used as a marker of breast CSCs to indicate poor prognosis in breast cancer patients ${ }^{32,33}$. In addition, $\mathrm{ABC}$ transporter G2 (ABCG2), chemokine receptor type 4 (CXCR4), and epithelial cell adhesion molecule (EpCAM) are regarded as markers of CSCs because they are often highly expressed in breast $\mathrm{CSCs}^{34-36}$. The results showed that the CSCs (MCF-7 CSCs and SKBR-3 CSCs) exhibited high expression of stemness markers $\left(\mathrm{CD} 44^{+} \mathrm{CD}_{2} 4^{-}, \mathrm{CXCR}^{+}, \mathrm{ABCG}^{+}\right.$, and $\left.\mathrm{EpCAM}^{+}\right)$ compared with the breast cancer cells (MCF-7 and SKBR-3). After treating the CSCs, the stemness markers were evidently decreased, demonstrating that the breast cancer stem cells were differentiated into mature cancer cells in vitro.

The expression levels of stemness markers in tumor tissues treated by functional dendrisomes carrying ATRA were significantly decreased compared with those treated by physiological saline $\left(\mathrm{CD} 44^{+} \mathrm{CD} 24^{-}, 6.43 \pm 0.61 \%\right.$ vs. $30.67 \pm 4.18 \%$, Fig. 5b1; CXCR4 $4^{+}, 74.68 \pm 0.83 \%$ vs. $92.72 \pm 0.35 \%$, Fig. 5b2). Furthermore, functional dendrisomes carrying ATRA produced a superior differentiation effect compared with that produced by regular dendrisomes carrying ATRA $\left(\mathrm{CD} 44^{+} \mathrm{CD}^{-} 4^{-}, 6.43 \pm 0.61 \%\right.$ vs. $11.59 \pm 1.76 \%$, Fig. $5 \mathrm{~b} 1$; CXCR $4^{+}, 74.68 \pm 0.83 \%$ vs. $87.64 \pm 0.85 \%$, Fig. $5 \mathrm{~b} 2)$. The results further demonstrated that the functional dendrisomes carrying ATRA were able to induce the differentiation of CSCs into mature cancer cells in vivo.

\section{Functional dendrisomes carrying ATRA induce the differentiation of breast CSCs by cell-cycle arrest through the retinoic acid signaling pathway}

To confirm the bioprocess of differentiation, a cell-cycle arrest assay was performed on the breast cancer cells (MCF-7), CSCs (MCF-7 CSCs), and DMCs (MCF-7 DMCs) by flow cytometry (Fig. 6a). The results showed that the functional dendrisomes carrying ATRA resulted in a remarkable cell-cycle arrest of CSCs at the G0/G1 phase (CSCs $53.19 \pm 0.99 \%$ vs. DMCs $80.97 \pm 0.60 \%$ ), demonstrating that cell-cycle arrest was involved in differentiation.

To reveal the mechanism, mRNA and protein markers involved in the retinoic acid signaling pathway were measured on breast cancer cells (MCF-7 and SK-BR-3), CSCs (MCF-7 CSCs and SK-BR-3 CSCs), and DMCs (MCF-7 DMCs and SK-BR-3 DMCs) using real-time qRT-PCR (primer sequences, Supplementary Table S2) and western blotting analysis, respectively. The results from qRT-PCR showed that the functional dendrisomes carrying ATRA significantly upregulated the mRNA expression of RAR $\alpha$ and $\mathrm{p} 21$ and downregulated the mRNA expression of CDK2 and cyclin E in DMCs compared with that in CSCs (Fig. 6b). Similarly, the results from western blotting showed that the functional dendrisomes carrying ATRA significantly upregulated the protein expression of $\mathrm{RaR} \alpha$ and $\mathrm{p} 21$ and downregulated the protein expression of CDK2 and Cyclin E in DMCs compared with that in CSCs (Fig. 6c).

The signaling pathway of differentiation can be explained by a cascade of reactions: (i) the released ATRA specifically binds with CRABP, which transports ATRA across the nucleus membrane; (ii) ATRA binds specifically with the retinoic acid receptor $\alpha(R A R \alpha)$ in the nucleus, and RAR $\alpha$ further binds with the retinoid $\mathrm{X}$ receptors (RXRs) to form heterodimers; ${ }^{37}$ and (iii) the heterodimers bind with the retinoic acid response elements (RAREs) to regulate specific genes ${ }^{38}$. Accordingly, the reactions upregulate the cell-cycle protein p21, which further downregulates the cyclin-dependent kinase complex (cyclin E/CDK2 complex), leading to cell-cycle arrest at $\mathrm{G} 0 / \mathrm{G1}^{39,40}$. Therefore, the results demonstrate that the functional dendrisomes carrying ATRA induce the differentiation of breast CSCs by cell cycle arrest via activating the retinoic acid signaling pathway. 

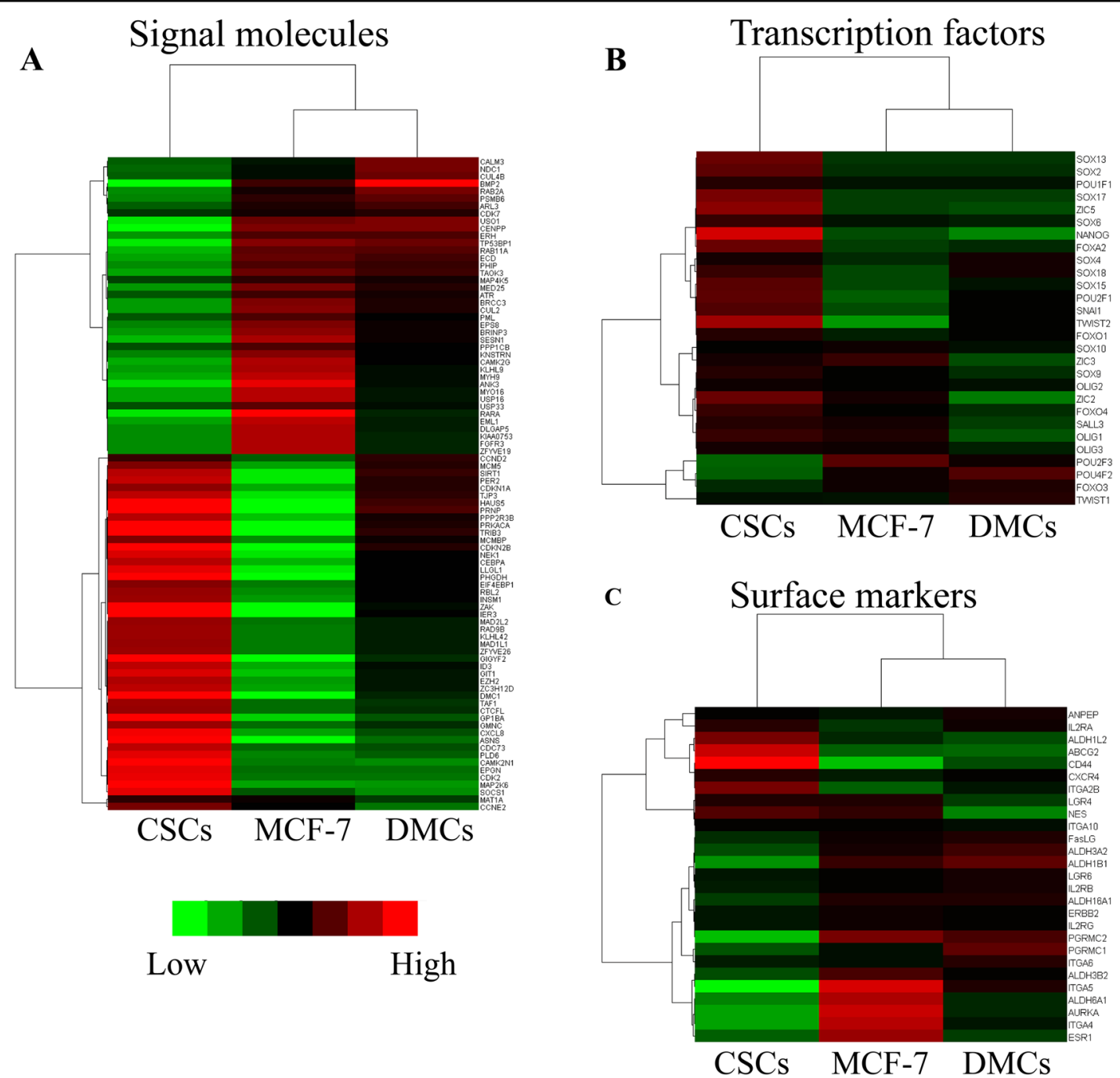

D

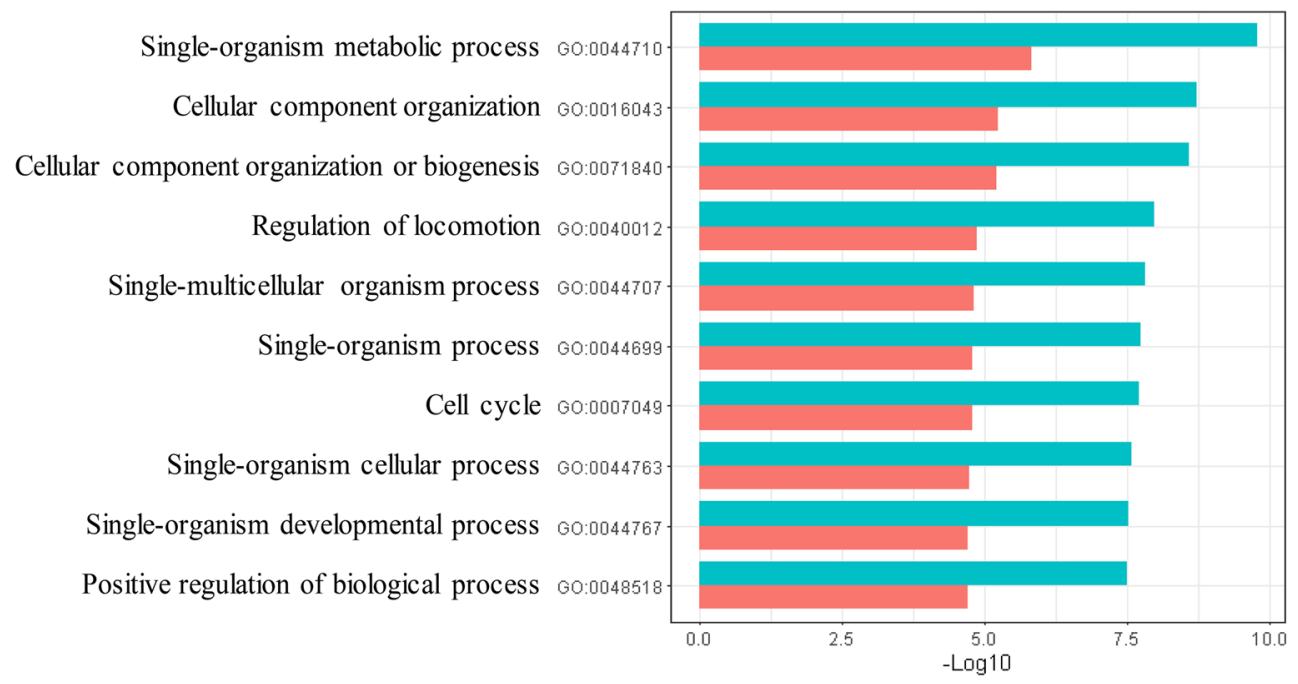

Fig. 4 (See legend on next page.) 
(see figure on previous page)

Fig. 4 Transcriptome profiling reveals the functional molecules and biological processes in differentiation of breast CSCs after treatment with functional dendrisomes carrying ATRA. The profiling study was performed on human breast cancer cells (MCF-7, as a control), breast cancer stem cells (CSCs), and differentiated mature cells (DMCs) using transcriptome microarray with Gene Ontology (GO) enrichment analysis. a The involved signal molecules during the differentiation. The results demonstrate that the functional dendrisomes carrying ARTA result in significant changes in a total of 1578 signal markers (genes), in which a substantial signal markers are involved in the differentiation, including ATRA receptorrelated marker (RARa, etc.), and cell cycle arrest-related markers (CDKN1a, CDK2, CCNE, etc.). $\mathbf{b}$ The involved transcription factor in the differentiation. The results exhibit that a number of transcription factors are involved in the differentiation, including stemness genes (SOX15, POU5F1, KLF5, OLIG3, SOX2, etc.). $\mathbf{c}$ The involved surface maker after differentiation. The results indicate that the stemness surface markers are significantly downregulated (CD44, CXCR4, ITGA2B, ALDH1B1, etc.), while the mature cancer surface markers are upregulated, demonstrating the differentiation of cancer stem cells into mature cancer cells. d Gene Ontology (GO) enrichment analysis. The results indicate that cell cycle is involved in the differentiation

\section{Functional dendrisomes carrying ATRA enhance anticancer effects in breast CSCs and in breast cancer-bearing mice}

Well-differentiated cancer cells are often more sensitive to chemotherapy. To confirm the differentiation therapy effect in our study, a cytotoxicity assay was performed on breast cancer stem cells (MCF-7 CSCs and SK-BR-3 CSCs, Fig. 7a1). The results showed that DTX alone exhibited a negligible effect at $1 \mathrm{nM}$ and a restricted killing effect at $10 \mathrm{nM}$ (30\%). After co-treatment with ATRA $(1-20 \mu \mathrm{M})$, the killing effect of DTX was evidently increased, showing an ATRA concentration dependence. To apply dendrisome formulations, co-treatment of ATRA with DTX showed a similar trend (MCF-7 CSCs and SK-BR-3 CSCs, Fig. 7a2). Furthermore, the functional dendrisomes carrying ATRA (a fixed concentration of $10 \mu \mathrm{M})$ and DTX (0.5-100 nM) demonstrated a stronger killing effect on the CSCs than did the control, indicating that the functional dendrisomes carrying ATRA significantly enhanced the anticancer efficacy of DTX in the CSCs in vitro.

Furthermore, an apoptosis assay was performed on the breast cancer stem cells (MCF-7 CSCs, Fig. 7b1; SK-BR-3 CSCs, Fig. 7b2). The results showed that the co-treatment of ATRA with DTX significantly enhanced the apoptosis of the CSCs. In addition, functional dendrisomes carrying ATRA and DTX significantly enhanced apoptosis of the CSCs in vitro, thereby contributing to the overall killing effect in the CSCs.

To simulate the killing effect in vivo, functional dendrisomes carrying ATRA and DTX were applied to breast CSC spheres in vitro (MCF-7 CSCs and SK-BR-3 CSC spheres, Fig. 7c). The results showed that the functional dendrisomes carrying ATRA and DTX were able to damage the CSC spheres, destroy the structure, and kill the cells, indicating a stronge damage effect compared with that of the control.

As an overall function verification, the efficacy of differentiation therapy was confirmed in breast cancerbearing mice. The results from the breast cancer-bearing nude mice demonstrated that the intravenous administration (free ATRA plus free DTX; functional dendrisomes carrying ATRA; functional dendrisomes carrying DTX; and functional dendrisomes carrying ATRA and
DTX) significantly inhibited the tumor volumes (Fig. 7d). Functional dendrisomes carrying ATRA and DTX exhibited the strongest inhibitory effect. Accordingly, the relative tumor weights at day 22 since the cancer inoculation were $92.59 \pm 4.44 \%, 62.89 \pm 7.56 \%, 63.84 \pm 8.71 \%$, $48.12 \pm 6.59 \%$ and $35.06 \pm 5.69 \%$, respectively (Supplementary Fig. S13). The results demonstrated that the functional dendrisomes carrying ATRA and DTX were the most efficacious in inhibiting tumor growth in cancerbearing mice.

In addition, the in vivo apoptosis after each treatment was evaluated on the isolated tumor tissues with the terminal deoxynucleotidyl transferase dUTP nick endlabeling (TUNEL) assay under a confocal laser-scanning fluorescence microscope (Fig. 7e). After intravenous administration (physiological saline; free ATRA plus free DTX; dendrisomes carrying ATRA and DTX; and functional dendrisomes carrying ATRA and DTX), the apoptotic rates in the tumor tissues were $1.04 \%, 5.06 \%, 9.61 \%$, and $14.95 \%$, respectively. The results demonstrated that the functional dendrisomes carrying ATRA and DTX resulted in the strongest apoptosis in the cancerbearing mice.

The cytotoxicity study demonstrated that the functional dendrisomes carrying ATRA and DTX were the most efficacious in killing both cancer cells and CSCs, thus depicting the effect of differentiation therapy in vitro. This treatment resulted in very significant apoptosis in the CSCs and a remarkable destructive effect on the CSC spheres in vitro, demonstrating that the differentiation therapy significantly enhanced the killing effect in breast CSCs. The enhanced effect was mainly due to the delivery capability and long-circulation effect of functional dendrisomes. Therefore, ATRA and DTX were efficiently delivered to the tumor site, penetrated into the tumor tissue, and were internalized by both cancer cells and CSCs.

\section{Functional dendrisomes are a safe drug carrier in vitro and in breast cancer-bearing mice}

To address the safety concern, as a preliminary safety evaluation, the cytotoxicity of the basic dendrimer material $(\mathrm{AD})$ of the functional dendrisomes was performed on 

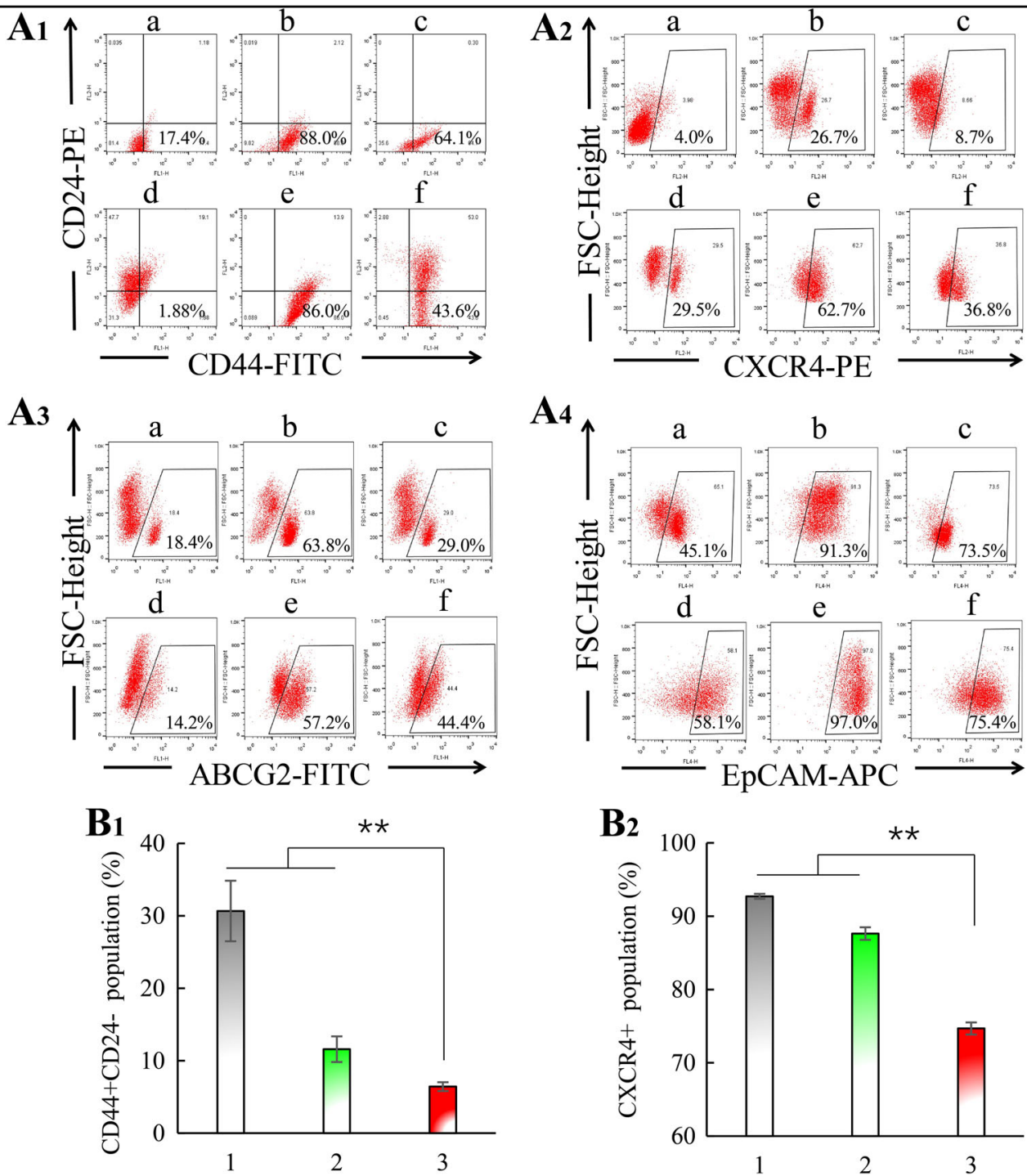

Fig. 5 The phenotype analysis demonstrates the differentiation of CSCs in vitro and in breast cancer-bearing mice after treatment with functional dendrisomes carrying ATRA. a The changes in phenotype markers in two kinds of CSCs after the treatment. The dot plots in the abscissa showed the expressions of CD44 (a1), CXCR4 (a2), ABCG2 (a3), and EpCAM (a4). (a) MCF-7; (b) MCF-7 CSCs; (c) MCF-7 DMCs; (d) SK-BR-3; (e) SK-BR-3 CSCs; (f) SK-BR-3 DMCs. DMCs represent the differentiated mature cells from CSCs after the treatment. The results demonstrate that the functional dendrisomes carrying ATRA enable to downregulate the stemness makers (CD44, CXCR4, ABCG2, EpCAM), indicating the differentiation of CSCs into mature cancer cells. $\mathbf{b}$ The changes in phenotype markers of CD44 (b1) and CXCR4 (b2) in the cancer-bearing mice after the treatment. The cancer-bearing nude mice were established by xenografted with MCF-7 CSCs cells, randomly divided into three groups (each three mice), and intravenously administrated with physiological saline (blank control), dendrisomes carrying ATRA (regular control), and functional dendrisomes carrying ATRA via tail vein. The dose of ATRA was $1 \mathrm{mg} / \mathrm{kg}$. 1, saline; 2, dendrisomes carrying ATRA; 3, functional dendrisomes carrying ATRA. The data are presented as mean \pm standard deviation $(n=3)$. ${ }^{*} P<0.01$. The results demonstrate that the functional dendrisomes carrying ATRA result in the most significant decrease in stemness markers (CD44+CD24-, CXCR4+) as compared with the control

normal breast cells (MCF-10A human mammary gland epithelial cells), breast cancer cells (MDA-MB-435S), and breast cancer stem cells (MCF-7 CSCs and SK-BR-3 $\mathrm{CSCs}$ ) in vitro. The results showed that the dendrimer $\mathrm{AD}$ (in the range of $0.01-10.0 \mathrm{mM}$ ) did not significantly affect the growth of all the cells, including normal breast cells, breast cancer cells, and breast cancer stem cells (Supplementary Fig. S14A).
To evaluate in vivo safety, body weight measurements, routine blood analysis, and histology analysis were performed on breast cancer-bearing mice. The results showed that all treatments did not markedly influence the body weight of the mice (Supplementary Fig. S14B). Moreover, routine blood analysis showed that treatment with free ATRA plus free DTX caused the rise in white blood cells and plateletcrit and that treatment with 

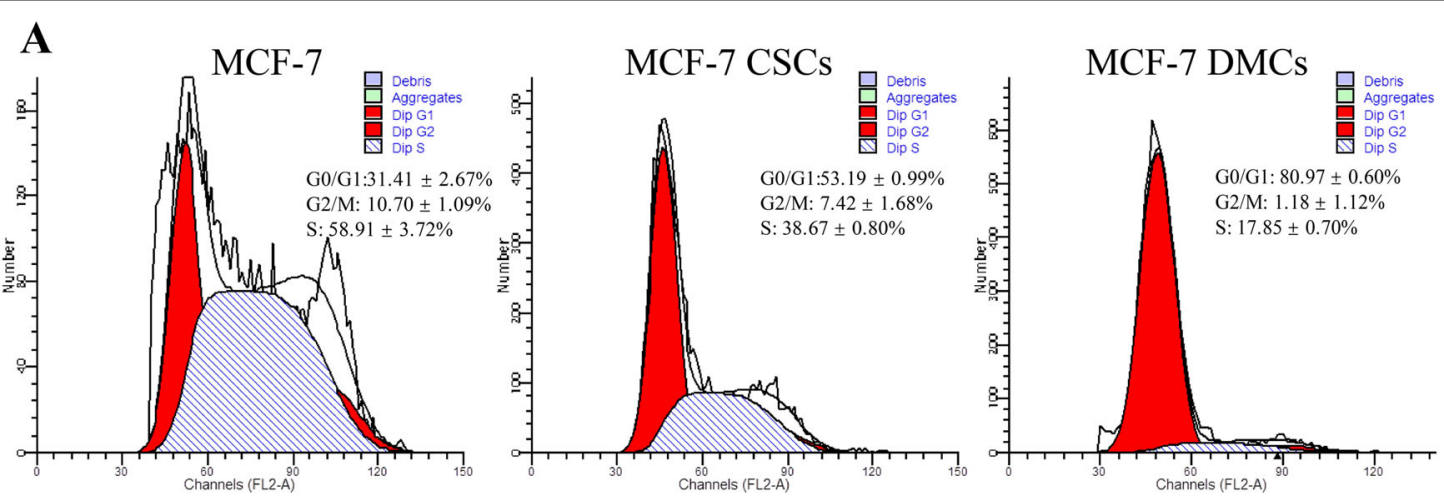

$\mathbf{B}_{1}$

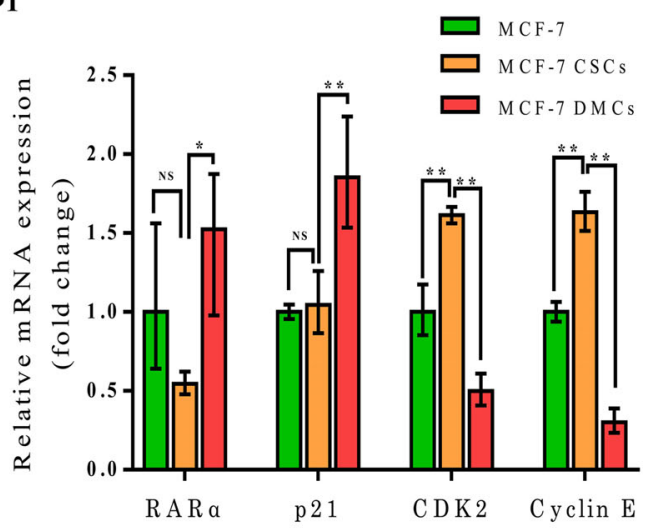

C

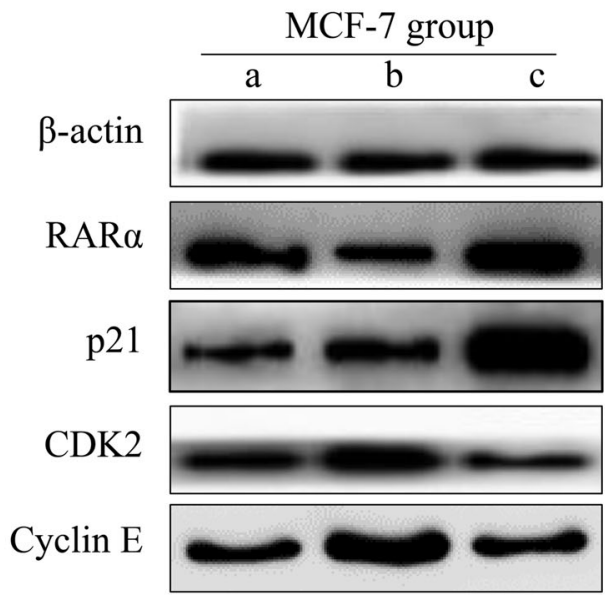

$\mathbf{B}_{2}$

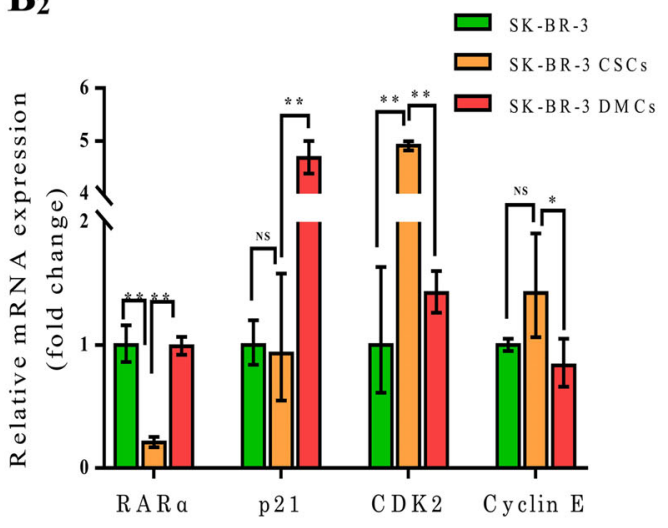

SK-BR-3 group
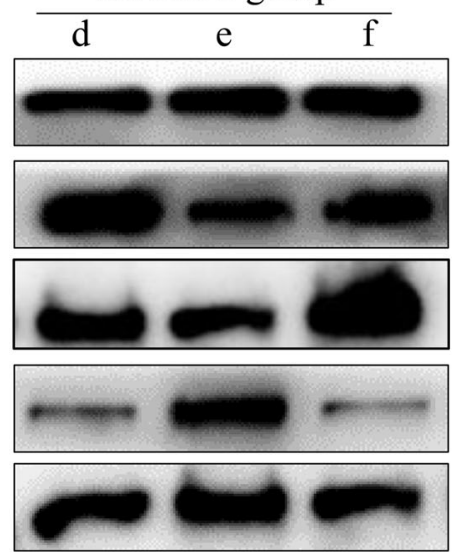

Fig. 6 Functional dendrisomes carrying ATRA induce the differentiation of CSCs by cell-cycle arrest through activating retinoic acid (RA) signaling pathway. a Cell-cycle arrest after treatment. The results from flow-cytometry demonstrate that the functional dendrisomes carrying ATRA lead to $88.01 \%$ cell-cycle arrest in the G0/G1 phase, indicating a significant cell-cycle arrest in DMCs as compared with untreated cancer cells (MCF-7 cells) or cancer stem cells (MCF-7 CSCs). DMCs represents the differentiated mature cells. $\mathbf{b}$ mRNA expressions involved in the retinoic acid (RA) signaling pathway after the treatment. The study was performed on breast cancer cells (MCF-7, SK-BR-3), breast cancer stem cells (MCF-7 CSCS, SK-BR3 CSCs), and differentiated mature cells (MCF-7 DMCs, SK-BR-3 DMCs). b1 human breast cancer MCF-7 cells, b2 human breast cancer SK-BR-3 cells. The data are presented as mean \pm standard deviation $(n=3)$. NS not significant; ${ }^{*} P<0.05$; ${ }^{*} P<0.01$. The results from qRT-PCR exhibit that the functional dendrisomes carrying ATRA significantly upregulate mRNA expressions of RARa and p21, while downregulate mRNA expressions of CDK2 and Cyclin E in DMCs as compared with those in CSCs, respectively. $\mathbf{c}$ Protein markers involved in the RA signaling pathway after the treatment. The results from western blotting exhibit that the functional dendrisomes carrying ATRA significantly upregulate protein expressions of RaRa and p21, while downregulate protein expressions of CDK2 and Cyclin E in DMCs as compared with those in CSCs, respectively 


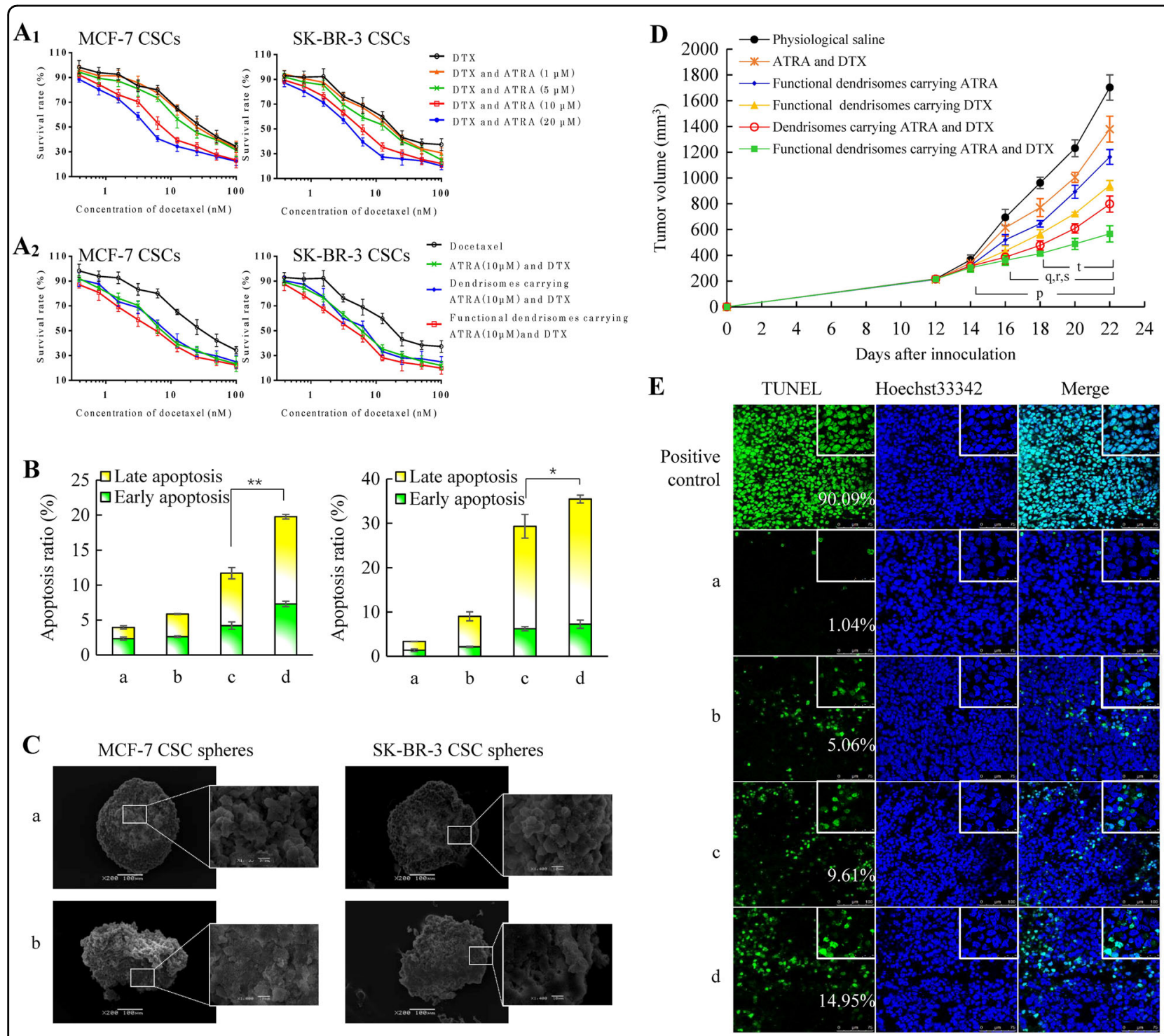

Fig. 7 Functional dendrisomes carrying ATRA enhance anticancer effect of chemotherapy in breast cancer stem cells and in cancerbearing mice. a Cytotoxicity in CSCs in vitro. a1 Cytotoxicity in MCF-7 CSCS or SK-BR-3 CSCS after treatment with free drugs; a2 cytotoxicity in MCF-7 CSCS or SK-BR-3 CSCS after treatment with functional dendrisomes carrying ATRA and DTX. The results exhibit that ATRA is able to enhance cytotoxicity of docetaxel (DTX), and the functional dendrisomes carrying ATRA and DTX have the strongest efficacy in killing breast cancer stem cells. b Apoptosis in CSCs in vitro. b1 apoptosis in MCF-7 CSCs; b2 apoptosis in SK-BR-3 CSCs. (a) untreated; (b) free ATRA plus free DTX; c dendrisomes carrying ATRA and DTX; $\mathbf{d}$ functional dendrisomes carrying ATRA and DTX. ${ }^{*} P<0.05,{ }^{* *} P<0.01$. Data are presented as mean \pm standard deviation $(n$ $=3$ ). The results demonstrate that the dendrisomes carrying ATRA and DTX are capable of increasing apoptosis of CSCs, thereby contributing to the killing effect on CSCS. c Destruction of CSCS sphere in vitro. The results exhibit that the functional dendrisomes carrying ATRA and DTX significantly destruct the CSCs spheres, leading to loosed structures and irregular shapes. $\mathbf{d}$ Anticancer efficacy in cancer-bearing nude mice. $P<0.05$; $(p)$ vs. physiological saline; (q) vs. ATRA and DTX; (r) vs. functional dendrisomes carrying ATRA; $(s)$ vs. functional dendrisomes carrying DTX; (t) vs. dendrisomes carrying ATRA and DTX. The data are presented as mean \pm standard deviation $(n=6)$. The results demonstrate that functional dendrisomes carrying ATRA and DTX have the strongest efficacy in inhibiting the tumor growth. e Apoptosis in the tumor tissues of breast cancerbearing nude mice. (a) Physiological saline; (b) free ATRA plus free DTX; (c) dendrisomes carrying ATRA and DTX; (d) functional dendrisomes carrying ATRA and DTX. The results indicate that the functional dendrisomes carrying ATRA and DTX result in the strongest apoptosis in the tumor tissues

functional dendrisomes carrying DTX caused a rise in plateletcrit and a decrease in lymphocytes. However, the treatment with functional dendrisomes carrying ATRA and DTX did not alter all blood indicators
(Supplementary Table S3). In addition, the results from the pathology analysis demonstrated that only treatment with free ATRA and free DTX caused obvious damage to lung tissue. The results from the organ analysis 
demonstrated that the treatment with all dendrisome formulations did not affect the major organs (Supplementary Fig. S14C). The in vivo study confirmed that the functional dendrisomes carrying ATRA and DTX did not significantly affect the blood indicators, body weight, or major organs of the cancer-bearing mice. In contrast, the toxicity in blood indicators was mainly caused by administration of the free drug formulation (free ATRA plus free DTX).

\section{Conclusions}

In conclusion, we report a new type of functional dendrisome constructed by synthesizing an amphiphilic dendrimer, which enhances the cellular uptake of CSCs, differentiates CSCs by carrying ATRA, and enhances anticancer efficacy by carrying ATRA and DTX. Our data reveal the cellular uptake mechanism of functional dendrisomes by breast CSCs and uncover the differentiation mechanism and the relevant signal molecules, transcription factors, and the cell cycle-associated signaling pathway. This study offers a novel solution to the elimination of breast CSCs using differentiation therapy and has significant clinical implications.

\section{Acknowledgements}

We would like to thank L. Su, X.R. Jia, L. Yuan, and L.Z. Xu for their technical assistance in conducting the FACS, confocal microscopy and in vivo imaging experiments. This work was supported by the Beijing Natural Science Foundation (Key Grant No. 7181004) and the National Natural Science Foundation of China (Grant no. 81673367 and 81874303).

\section{Conflict of interest}

The authors declare that they have no conflict of interest.

\section{Publisher's note}

Springer Nature remains neutral with regard to jurisdictional claims in published maps and institutional affiliations.

Supplementary information is available for this paper at https://doi.org/ 10.1038/s41427-019-0134-x.

Received: 26 January 2019 Revised: 24 March 2019 Accepted: 8 May 2019. Published online: 5 July 2019

\section{References}

1. Sreepadmanabh, M. et al. Investigations into the cancer stem cell niche using in-vitro 3-D tumor models and microfluidics. Biotechnol. Adv. 36, 1094-1110 (2018).

2. Charafe-Jauffret, E. et al. ALDH1-positive cancer stem cells predict engraftment of primary breast tumors and are governed by a common stem cell program. Cancer Res. 73, 7290-7300 (2013).

3. Yamamoto, M. et al. NF-KB non-cell-autonomously regulates cancer stem cell populations in the basal-like breast cancer subtype. Nat. Commun. 4, 2299 (2013).

4. Flemming, A. Cancer stem cells: targeting the root of cancer relapse. Nat. Rev. Drug Discov. 14, 165 (2015).

5. Dean, M. et al. Tumour stem cells and drug resistance. Nat. Rev. Cancer $\mathbf{5}$ 275-284 (2005).
6. Kinsella, T. J. Coordination of DNA mismatch repair and base excision repair processing of chemotherapy and radiation damage for targeting resistant cancers. Clin. Cancer Res. 15, 1853-1859 (2009).

7. Siegel, R. L. et al. Cancer statistics. CA Cancer J. Clin. 68, 7-30 (2018).

8. Pack, D. W. et al. Design and development of polymers for gene delivery. Nat. Rev. Drug Discov. 4, 581-593 (2005).

9. Lee, C. C. et al. Designing dendrimers for biological applications. Nat. Biotechnol. 23, 1517-1526 (2005).

10. Markman, J. L. et al. Nanomedicine therapeutic approaches to overcome cancer drug resistance. Adv. Drug Deliv. Rev. 65, 1866-1879 (2013).

11. Fang, J. et al. The EPR effect: unique features of tumor blood vessels for drug delivery, factors involved, and limitations and augmentation of the effect. Adv. Drug Deliv. Rev. 63, 136-151 (2011).

12. Genchi, G. An overview on D-amino acids. Amino Acids 49, 1521-1533 (2017).

13. Senior, J. \& Gregoriadis, G. Stability of small unilamellar liposomes in serum and clearance from the circulation: the effect of the phospholipid and cholesterol components. Life Sci. 30, 2123-2136 (1982).

14. Allenby, G. et al. Retinoic acid receptors and retinoid X receptors: interactions with endogenous retinoic acids. Proc. Natl Acad. Sci. USA 90, 30-34 (1993).

15. Tallman, M. S. et al. Acute promyelocytic leukemia: evolving therapeutic strategies. Blood 99, 759-767 (2002).

16. Mirza, N. et al. All-trans-retinoic acid improves differentiation of myeloid cells and immune response in cancer patients. Cancer Res. 66, 9299-9307 (2006).

17. Qi, W. X. et al. Paclitaxel-based versus docetaxel-based regimens in metastatic breast cancer: a systematic review and meta-analysis of randomized controlled trials. Curr. Med. Res. Opin. 29, 117-125 (2013).

18. Wang, $\mathrm{H}$. et al. Multiple mechanisms underlying aquired resistance to taxanes in selected docetaxel resistant MCF-7 breast cancer cells. BMC Cancer 14, 37 (2014).

19. Maeda, H. Toward a full understanding of the EPR effect in primary and metastatic tumors as well as issues related to its heterogeneity. Adv. Drug Deliv. Rev. 91, 3-6 (2015).

20. Rothbard, J. B. et al. Conjugation of arginine oligomers to cyclosporin A facilitates topical delivery and inhibition of inflammation. Nat. Med. 6 1253-1257 (2000)

21. Chapman, D. \& Quinn, P. J. A method for the modulation of membrane fluidity: homogeneous catalytic hydrogenation of phospholipids and phospholipids and phospholipid-water model biomembranes. Proc. Natl Acad. Sci. USA. 73, 3971-3975 (1976).

22. Kastantin, M. et al. Effect of the lipid chain melting transition on the stability of DSPE-PEG (2000) micelles. Langmuir 25, 7279-7286 (2009).

23. Li, S. D. \& Huang, L. Nanoparticles evading the reticuloendothelial system: role of the supported bilayer. Biochim. Biophys. Acta 1788, 2259-2266 (2009).

24. $\mathrm{Mu}, \mathrm{L}$. M. et al. Dual-functional drug liposomes in treatment of resistant cancers. Adv. Drug Deliv. Rev. 115, 46-56 (2017)

25. McMahon, H. T. \& Boucrot, E. Molecular mechanism and physiological functions of clathrin-mediated endocytosis. Nat. Rev. Mol. Cell Biol. 12, 517-533 (2011).

26. Pastuszkac, M. K., Okamoto, C. T., Hamm-Alvarez, S. F. \& MacKay, J. A. Flipping the switch on clathrin-mediated endocytosis using thermally responsive protein microdomains. Adv. Funct. Mater. 24, 5340-5347 (2014).

27. Baisa, G. A., Mayers, J. R. \& Bednarek, S. Y. Curr. Opin. Budding and braking news about clathrin-mediated endocytosis. Plant Biol. 16, 718-725 (2013).

28. Nel, A. E. et al. Understanding biophysicochemical interactions at the nano-bio interface. Nat. Mater. 8, 543-557 (2009).

29. Sun, P. Z. et al. Highly selective charge-guided ion transport through a hybrid membrane consisting of anionic graphene oxide and cationic hydroxide nanosheet superlattice units. NPG Asia Mater. 8, e259 (2016).

30. Li, W. Q. et al. Preoccupation of empty carriers decreases endo-/lysosome escape and reduces the protein delivery efficiency of mesoporous silica nanoparticles. ACS Appl. Mater. Interfaces 10, 5340-5347 (2018).

31. Leid, $\mathbf{M}$. et al. Multiplicity generates diversity in the retinoic acid signalling pathways. Trends Biochem. Sci. 17, 427-433 (1992).

32. Li, F. et al. Beyond tumorigenesis: cancer stem cells in metastasis. Cell Res. 17 3-14 (2007)

33. Jaggupilli, A. \& Elkord, E. Significance of CD44 and CD24 as cancer stem cell markers: an enduring ambiguity. Clin. Dev. Immunol. 2012, 708036 (2012).

34. Patrawala, L. et al. Side population is enriched in tumorigenic, stem-like cancer cells, whereas $\mathrm{ABCG}+$ and $\mathrm{ABCG}$ - cancer cells are similarly tumorigenic. Cancer Res. 65, 6207-6219 (2005). 
35. Yi, T. F. et al. Quantitative phosphoproteomic analysis reveals system-wide signaling pathways downstream of SDF-1/CXCR4 in breast cancer stem cells. Proc. Natl Acad. Sci. USA. 111, 2182-2190 (2014).

36. Osta, W. A. et al. EpCAM is overexpressed in breast cancer and is a potentia target for breast cancer gene therapy. Cancer Res. 64, 5818-5824 (2004).

37. Zhang, X. K. et al. Retinoid X receptor is an auxiliary protein for thyroid hormone and retinoic acid receptors. Nature 355, 441-446 (1992).
38. Zelent, A. et al. Translocations of the RAR alpha gene in acute promyelocytic leukemia. Oncogene 20, 7186-7203 (2001).

39. Casini, T. \& Pelicci, P. G. A function of p21 during promyelocytic leukemia cell differentiation independent of CDK inhibition and cell cycle arrest. Oncogene 18, 3235-3243 (1999).

40. Seewaldt, V. L. et al. All-trans-retinoic acid mediates G1 arrest but not apoptosis of normal human mammary epithelial cells. Cell Growth Differ. 8, 631-641 (1997). 